\title{
Does robot-assisted navigation influence pedicle screw selection and accuracy in minimally invasive spine surgery?
}

\author{
Karim A. Shafi, MD, Yuri A. Pompeu, MD, PhD, Avani S. Vaishnav, MBBS, Eric Mai, BS, \\ Ahilan Sivaganesan, MD, Pratyush Shahi, MBBS, MS, and Sheeraz A. Qureshi, MD, MBA \\ Hospital for Special Surgery, New York, New York
}

OBJECTIVE The accuracy of percutaneous pedicle screw placement has increased with the advent of robotic and surgical navigation technologies. However, the effect of robotic intraoperative screw size and trajectory templating remains unclear. The purpose of this study was to compare pedicle screw sizes and accuracy of placement using robotic navigation (RN) versus skin-based intraoperative navigation (ION) alone in minimally invasive lumbar fusion procedures.

METHODS A retrospective cohort study was conducted using a single-institution registry of spine procedures performed over a 4-year period. Patients who underwent 1- or 2-level primary or revision minimally invasive surgery (MIS)transforaminal lumbar interbody fusion (TLIF) with pedicle screw placement, via either robotic assistance or surgical navigation alone, were included. Demographic, surgical, and radiographic data were collected. Pedicle screw type, quantity, length, diameter, and the presence of endplate breach or facet joint violation were assessed. Statistical analysis using the Student t-test and chi-square test was performed to evaluate the differences in pedicle screw sizes and the accuracy of placement between both groups.

RESULTS Overall, 222 patients were included, of whom 92 underwent RN and 130 underwent ION MIS-TLIF. A total of 403 and 534 pedicle screws were placed with RN and ION, respectively. The mean screw diameters were $7.25 \pm 0.81$ $\mathrm{mm}$ and $6.72 \pm 0.49 \mathrm{~mm}(p<0.001)$ for the RN and ION groups, respectively. The mean screw length was $48.4 \pm 4.48$ $\mathrm{mm}$ in the RN group and $45.6 \pm 3.46 \mathrm{~mm}$ in the ION group $(p<0.001)$. The rates of "ideal" pedicle screws in the RN and ION groups were comparable at $88.5 \%$ and $88.4 \%(p=0.969)$, respectively. The overall screw placement was also similar. The RN cohort had $63.7 \%$ screws rated as good and $31.4 \%$ as acceptable, while $66.1 \%$ of ION-placed screws had good placement and $28.7 \%$ had acceptable placement $(p=0.661$ and $p=0.595$, respectively). There was a significant reduction in high-grade breaches in the $\mathrm{RN}$ group $(0 \%, n=0)$ compared with the ION group $(1.2 \%, n=17, p=0.05)$.

CONCLUSIONS The results of this study suggest that robotic assistance allows for placement of screws with greater screw diameter and length compared with surgical navigation alone, although with similarly high accuracy. These findings have implied that robotic platforms may allow for safe placement of the "optimal screw," maximizing construct stability and, thus, the ability to obtain a successful fusion.

https://thejns.org/doi/abs/10.3171/2021.10.FOCUS21526

KEYWORDS fusion; technology; robotics; minimally invasive surgery

$\mathrm{S}$ INCE its approval in the mid-1990s, pedicle screw instrumentation has become the mainstay of fixation in patients with thoracic or lumbar spinal deformity, degeneration, or instability. ${ }^{1,2}$ Pedicle screws offer threecolumn fixation of the spine; while their pullout strength depends largely on bone quality, the screw length, diameter, and thread pitch are also contributing parameters. ${ }^{3,4}$ Therefore, the efficacy of pedicle screw constructs, with or without interbody devices, hinges on both appropriate screw selection and accuracy of placement. In general, inserting the longest and widest screw that may be safely placed within the confines of the pedicle and vertebral body will optimize fixation strength. Nevertheless, the benefits of larger screws must be weighed against the risks of iatrogenic pedicle fracture or injury to surrounding neurovascular structures..$^{2,5-7}$

Screw malposition, namely, a screw with biomechanically insufficient purchase or a screw that violates neuro-

ABBREVIATIONS ASA = American Society of Anesthesiologists; $\mathrm{CCI}=$ Charlson Comorbidity Index; ION = intraoperative navigation; MIS = minimally invasive surgery; REDCap = Research Electronic Data Capture; RN = robotic navigation; t-EMG = triggered electromyography; TLIF = transforaminal lumbar interbody fusion . ACCOMPANYING EDITORIAL DOI: 10.3171/2021.10.FOCUS21635.

SUBMITTED August 31, 2021. ACCEPTED October 14, 2021

INCLUDE WHEN CITING DOI: 10.3171/2021.10.FOCUS21526. 
logical or vascular structures, remains a concern with the use of percutaneous techniques. ${ }^{8}$ The advent of surgical navigation systems has helped mitigate these risks. More recently, robotic navigation (RN) surgery has demonstrated safe and accurate pedicle screw placement, streamlined workflow, and decreased radiation exposure and operative times. ${ }^{8-14}$ Several studies have demonstrated the increased accuracy of RN pedicle screw placement compared with fluoroscopy-based techniques. However, the effect of this technology on screw size selection has not been fully evaluated. Several robotic platforms allow for intraoperative stereotactic trajectory planning, allowing surgeons to visualize screw trajectory and assess pedicle fill in real time. The purpose of this study was to determine whether RN screw planning allows for selection of larger and longer screws. Additionally, the accuracy of RN screw placement was compared with skin-based intraoperative navigation (ION) alone.

\section{Methods}

\section{Patient Selection}

Following IRB approval, a retrospective review of a prospectively maintained database of spine surgeries was conducted to identify patients who underwent minimally invasive surgery (MIS)-transforaminal lumbar interbody fusion (TLIF). Procedures were performed between April 2017 and June 2021 via either RN or ION alone. Patients with symptomatic single- or multilevel spinal stenosis, with or without spondylolisthesis, or recurrent disc herniation, who underwent primary or revision MIS-TLIF were included (Qureshi-Louie class II). ${ }^{15}$ Those patients with neoplasm/malignancy, fracture, or a history of trauma were excluded. Bilateral percutaneous pedicle screw instrumentation was performed in all cases, and all cases were performed by the senior author (S.Q.). Preoperative demographic variables, including age, sex, BMI, type of insurance, Charlson Comorbidity Index (CCI) score, and American Society of Anesthesiologists (ASA) classification, were obtained.

\section{Surgical Data}

All ION procedures were performed using Stryker SpineMask Tracker, Stryker SpineMap 3D Software, and the Stryker NAV3i Platform (Stryker Corp.), a noninvasive, skin-based navigation system. All RN procedures were performed using the ExcelsiusGPS (Globus Medical, Inc.) RN platform. Following introduction of robotic technology at our institution in February 2019, all MIS-TLIF cases were subsequently performed with $\mathrm{RN}$ by default, unless maintenance, technical issues, or availability precluded its use. In all cases, MIS-TLIF was performed using tubular retractors and an expandable interbody cage with iliac crest autograft with posterior pedicle screw/rod fixation. Triggered electromyography (t-EMG) monitoring was performed following placement of all screws, using a nasopharyngeal EMG monitoring probe to stimulate the screw at $10.0 \mathrm{~mA}$, as an early assessment for the presence of a breach. ${ }^{16,17}$ Final anteroposterior and lateral fluoroscopic images were obtained after placement of all instrumentation.
The surgical data obtained included primary versus revision procedure; levels instrumented; and pedicle screw type, quantity, length, and diameter. Screw dimensions were obtained from the patients' electronic health record (Epic Systems), to which all operative implant records are uploaded. All data were collected, stored, and managed using Research Electronic Data Capture (REDCap) hosted at Weill Cornell Medicine Clinical and Translational Science Center supported by the NIH's National Center for Advancing Translational Science under award number UL1 TR002384. REDCap is a Health Insurance Portability and Accountability Act (HIPAA)-compliant web-based software platform created to provide an organized framework for data collection when conducting research studies. ${ }^{18}$

\section{ION Operative Technique}

Following induction of general anesthesia and intubation, patients were positioned prone on a radiolucent table (Jackson table with a Wilson frame). Sterile preparation and draping were performed, and the skin-based navigation tracker was placed. A 3D fluoroscopic spin was then performed using the Ziehm Vision RFD 3D (Ziehm Imaging, Inc.) to register surgical landmarks and anatomy. The remainder of the procedure, including pedicle screw and interbody placement, was performed using ION guidance with a calibrated pointer. Specifics regarding our preference of skin-based navigation and surgical steps have been detailed in previous literature. ${ }^{19-22}$

\section{RN Operative Technique}

For the RN technique, induction of anesthesia, patient positioning, and intraoperative 3D fluoroscopic spin were similarly performed as described above. The intraoperative scan was then uploaded to the robotic platform, which provides navigation and real-time instrumentation planning software. The robot was operated in a "sharedcontrol" mode, allowing for both the surgeon and robotic arm to dictate motions. ${ }^{23}$ Pedicle screw dimensions were templated using the patient-specific intraoperative plan and then placed using the floor-mounted robotic arm for guidance. The remainder of the procedure was performed using $\mathrm{RN}$ interbody cage placement, as described in prior publications..$^{14,24-26}$

\section{Radiographic Measurements}

All patients underwent postoperative lumbar CT with sagittal, axial, and coronal plane reconstructions. The radiographic metrics evaluated included pedicle screw accuracy and facet joint and/or endplate violation. For each screw, the presence of a superior/lateral breach, inferior/ medial breach, and tip breach was assessed and graded according to the Gertzbein-Robbins classification, the full description of which is included in Fig. $1 .{ }^{8}$ Facet violation and endplate breach were reported as dichotomous variables (yes/no). Lastly, each screw was assessed for overall placement and graded according to the simplified screw grading system ${ }^{27}$ (Table 1). A "good" pedicle screw had no pedicle (Gertzbein-Robbins grade A), tip, endplate, or facet breach. An "acceptable" screw had pedicle breach within a radiographic "safe zone" $(<4 \mathrm{~mm}$ superior/lat- 

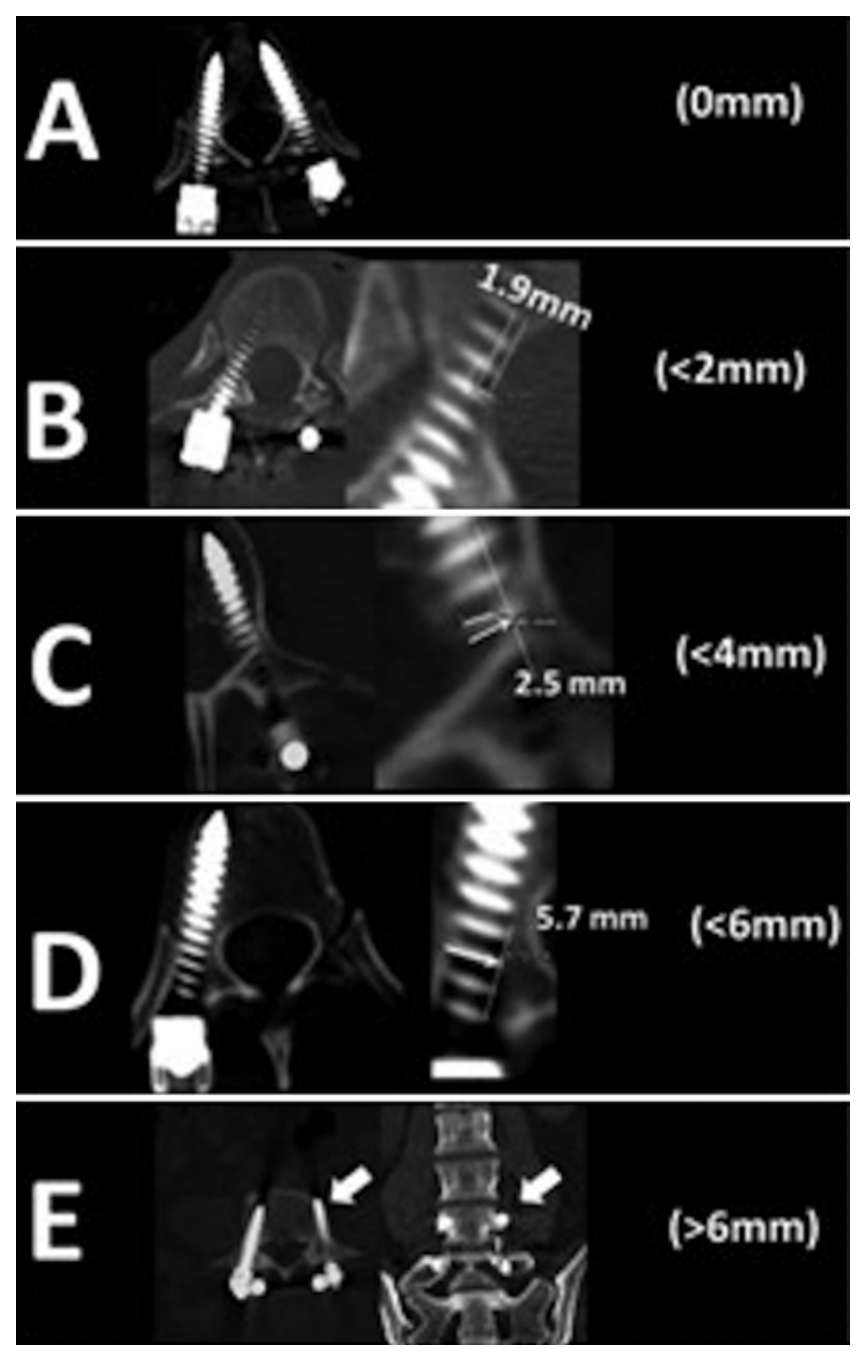

FIG. 1. Representative CT scans illustrating the Gertzbein-Robbins classification of an "ideal" intrapedicular trajectory. Grades A-E were assigned based on deviations of a screw from this trajectory. A: Grade A screws have no breach of the pedicle cortex in any direction. B: Grade B delineates a screw that violates the cortex of the pedicle with $<2 \mathrm{~mm}$ of breach. C and D: Grade C screws involve a 2- to 4-mm cortical breach (C), whereas grade D reflects 4-6 $\mathrm{mm}$ of cortical penetration (D). E: Grade $E$ describes a screw that contains $>6 \mathrm{~mm}$ of cortical breach. Reprinted from Schatlo B, Molliqaj G, Cuvinciuc V, Kotowski M, Schaller K, Tessitore E. J Neurosurg Spine. 2014;20(6):636-643. ${ }^{8}$ Copyright AANS. Published with permission.

eral breach or $<2 \mathrm{~mm}$ inferior/medial breach) or any distance of tip breach, whereas a "poor" screw contained any breach outside of the "safe zone" or facet joint violation involving the superior unfused level, or an endplate breach into an unfused level. CT scans were evaluated by three independent reviewers, an orthopedic spine fellow and two orthopedic surgery residents, who were blinded to cohort assignment.

\section{Statistical Analysis}

Descriptive statistics for the demographic and surgical data include means, standard deviations, and proportions. Pearson's chi-square test was used to analyze categorical
TABLE 1. Simplified screw grading system

\begin{tabular}{|c|c|}
\hline Score & Description \\
\hline Good & No tip, endplate, pedicle, or facet breach \\
\hline \multirow[t]{4}{*}{ Acceptable } & Pedicle breach w/in the radiographic safe zone \\
\hline & $<4 \mathrm{~mm}$ superior/lateral pedicle breach \\
\hline & $<2 \mathrm{~mm}$ inferior/medial pedicle breach \\
\hline & Any distance of tip breach \\
\hline \multirow[t]{5}{*}{ Poor } & Any breach outside of radiographic safe zone \\
\hline & $\geq 4 \mathrm{~mm}$ superior/lateral pedicle breach \\
\hline & $\geq 2 \mathrm{~mm}$ inferior/medial pedicle breach \\
\hline & Facet violation affecting the superior unfused level \\
\hline & Endplate breach into an unfused level \\
\hline
\end{tabular}

variables, including breach and Gertzbein-Robbins grades to compare patients who underwent $\mathrm{RN}$ with those who underwent ION MIS-TLIF. Continuous variables, including pedicle screw diameters and lengths, were compared using independent Student t-tests and were reported as means with standard deviations and minimum and maximum dimensions. No nonparametric tests were used for comparison as all continuous data were determined to be normally distributed. All analyses were conducted using IBM SPSS Statistics version 26.0 (IBM Corp.). All p values $<0.05$ were interpreted as statistically significant.

\section{Results}

\section{Patient Sample}

Overall, 222 patients who underwent a 1- or 2-level primary or revision MIS-TLIF were included in the study. Baseline demographic data were comparable between both the RN and ION groups (Table 2). The RN cohort included 92 patients, most of whom underwent primary procedures $(68.5 \%, \mathrm{n}=63)$. The ION cohort included 130 patients, the majority of whom also underwent primary procedures (75.4\%, $\mathrm{n}=98)$. In both the $\mathrm{RN}$ and ION groups, most cases involved 1 level (RN 82.6\%, $\mathrm{n}=76$; ION 86.9\%, $\mathrm{n}$ $=113) ; \mathrm{L} 4-5$ was the most commonly involved level $(\mathrm{RN}$ $57.4 \%, \mathrm{n}=62 ; \mathrm{ION} 61.2 \%, \mathrm{n}=90)$, followed by L5-S1 (RN $40.7 \%, \mathrm{n}=44 ;$ ION $38.7 \%, \mathrm{n}=56)($ Table 3$)$.

\section{Pedicle Screw Dimensions}

There were 403 screws placed in the RN cohort and 534 placed in the ION cohort. Screws placed with robotic assistance had both a larger screw diameter (RN 7.25 \pm 0.81 $\mathrm{mm}$ [range 5.5-8.5 mm]; ION $6.72 \pm 0.49$ [range 5.5-8.5 $\mathrm{mm}$ ]) and screw length (RN $48.4 \pm 4.48 \mathrm{~mm}$ [range 40-60 $\mathrm{mm}$ ]; ION $45.6 \pm 3.46 \mathrm{~mm}$ [range $35-55 \mathrm{~mm}$ ]) compared with screws placed with navigation alone $(\mathrm{p}<0.001,95 \%$ CI) (Table 3).

\section{Pedicle Screw Accuracy}

Based on the Gertzbein-Robbins classification of the "ideal" intrapedicular trajectory, pedicle screw accuracy was similar among cohorts; $88.5 \%(\mathrm{n}=270)$ of $\mathrm{RN}$ screws and $88.4 \%(\mathrm{n}=1217)$ of ION screws were grade $\mathrm{A}(\mathrm{p}=$ $0.969)$. There was no statistically significant difference in 
TABLE 2. Demographic data for patients who underwent RN and ION-alone MIS-TLIF

\begin{tabular}{|c|c|c|c|}
\hline & $\mathrm{RN}(\mathrm{n}=92)$ & $\operatorname{ION}(n=130)$ & $\mathrm{p}$ Value \\
\hline Mean age, yrs (SD) & $59.5(12.1)$ & $58.5(12.9)$ & 0.552 \\
\hline Male sex & $47(51.1)$ & $69(53.1)$ & 0.770 \\
\hline Mean BMI (SD) & $27.5(4.9)$ & $27.9(6.4)$ & 0.665 \\
\hline Insurance type & & & 0.208 \\
\hline Commercial/private & $62(67.4)$ & $100(76.9)$ & - \\
\hline Medicare & $29(31.5)$ & $25(19.2)$ & - \\
\hline Medicaid & 0 & $1(0.8)$ & - \\
\hline Workers' compensation & $1(1.1)$ & $3(2.3)$ & - \\
\hline Other & 0 & $1(0.8)$ & - \\
\hline $\mathrm{CCl}$ score & & & 0.403 \\
\hline $0-1$ & $74(80.4)$ & $111(85.4)$ & - \\
\hline $2-3$ & $17(18.5)$ & $17(13.1)$ & - \\
\hline$\geq 4$ & $1(1.1)$ & $2(1.6)$ & - \\
\hline ASA class & & & 0.881 \\
\hline 1 & $10(10.9)$ & $14(10.8)$ & - \\
\hline II & $78(84.8)$ & $112(86.2)$ & - \\
\hline III & $4(4.3)$ & $4(3.1)$ & - \\
\hline No. of TLIF levels & & & 0.373 \\
\hline 1 & $76(82.6)$ & $113(86.9)$ & - \\
\hline 2 & $16(17.4)$ & $17(13.1)$ & - \\
\hline Revision & $7(7.6)$ & $12(9.2)$ & 0.670 \\
\hline
\end{tabular}

Values represent the number of patients (\%) unless stated otherwise.

grade distribution across cohorts $(\mathrm{p}=0.217)$. Of note, there were no grade $\mathrm{E}$ screws in the RN group, while there were 17 in the ION group $(\mathrm{p}=0.051)$ (Table 4). Of the screws that were not "perfectly" intrapedicular (grades B-E), there was a higher percentage of superior/lateral breaches in the ION group $(54.7 \%$ vs $31.4 \%, p=0.243)$, whereas there were significantly more inferomedial breaches in the RN group ( $45.7 \%$ vs $17.0, \mathrm{p}=0.002)$ (Table 5). There was no statistically significant difference in overall screw placement; $63.7 \%$ and $31.4 \%$ of RN screws had good or acceptable placement, respectively, while $66.1 \%$ of ION screws had good placement and $28.7 \%$ had acceptable placement $(\mathrm{p}=0.661$ and $\mathrm{p}=0.595$, respectively). Of note, there was a $6.9 \%$ rate of endplate breach in the $\mathrm{RN}$ group and a $1.3 \%$ rate in the ION-alone group $(\mathrm{p}=0.001)$ (Table
TABLE 4. Gertzbein-Robbins grades for RN and ION-alone MISTLIFs

\begin{tabular}{lccccc}
\hline & Grade A & Grade B & Grade C & Grade D & Grade E \\
\hline $\mathrm{RN}, \mathrm{n}(\%)$ & $270(88.5)$ & $27(8.9)$ & $6(2.0)$ & $2(0.6)$ & $0(0)$ \\
\hline $\mathrm{ION}, \mathrm{n}(\%)$ & $1217(88.4)$ & $95(6.9)$ & $31(2.3)$ & $16(1.2)$ & $17(1.2)$ \\
\hline $\mathrm{p}$ value & 0.969 & 0.235 & 0.758 & 0.436 & 0.051 \\
\hline Overall p value & & & 0.217 & & \\
\hline
\end{tabular}

Pearson chi-square test statistic 5.766, df $4, p=0.217$.

6). Similarly, there were more facet joint violations in the RN cohort, with a rate of $5.0 \%$ compared with $1.3 \%$ in the ION-alone group $(\mathrm{p}=0.0017)$.

\section{Discussion}

This retrospective analysis demonstrated that pedicle screws with a larger diameter (mean RN $7.25 \mathrm{~mm}$ vs ION $6.72 \mathrm{~mm}, \mathrm{p}<0.001$ ) and length (mean RN $48.4 \mathrm{~mm}$ vs ION $45.6 \mathrm{~mm}, \mathrm{p}<0.001$ ) were used in RN MIS-TLIF compared with ION MIS-TLIF. Of note, this series demonstrated a higher rate of both endplate breaches and facet joint violations in the $\mathrm{RN}$ cohort, with rates of $6.9 \%$ versus $1.3 \%(\mathrm{p}<0.001)$ and $5.0 \%$ versus $1.3 \%(\mathrm{p}<0.001)$, respectively. However, there were no Gertzbein-Robbins grade $\mathrm{E}$ scores $(\geq 6 \mathrm{~mm})$ in the $\mathrm{RN}$ group, whereas there were 17 in the ION group $(p=0.051)$. With regard to the simplified screw grading system, the rates of screws classified as good (RN 63.7\% vs ION 66.1\%, p $=0.661$ ) or acceptable (RN $31.4 \%$ vs ION $28.7 \%, p=0.595$ ) were comparable between both groups; there was no statistically significant difference in overall screw placement $(p=0.839)$. The results from this study suggest that RN allows for the placement of both larger-diameter and longer screws and that RN systems allow for a similarly high safety and accuracy profile when compared with ION.

The goal in pedicle screw instrumentation, regardless of technique, is to obtain maximal osseous purchase, particularly in aging patients with poor bone quality. While bony architecture plays a significant role in the pullout strength of pedicle screws, prior studies have demonstrated increased fixation strength with increasing screw outer diameter and length..$^{28} \mathrm{~A}$ cadaveric study of 39 osteoporotic lumbar spines by Kueny et al. reported an increased pullout force of $24 \%$ with a $1-\mathrm{mm}$ increase in size

TABLE 3. Pedicle screw sizes for RN and ION-alone MIS-TLIFs

\begin{tabular}{|c|c|c|c|c|c|c|c|c|c|}
\hline & \multicolumn{3}{|c|}{ Total } & \multicolumn{3}{|c|}{ L4-5 } & \multicolumn{3}{|c|}{ L5-S1 } \\
\hline & RN & ION & $p$ Value & $\mathrm{RN}$ & ION & $p$ Value & $\mathrm{RN}$ & ION & $p$ Value \\
\hline No. of fusions & 108 & 147 & & 62 & 90 & & 44 & 56 & \\
\hline No. of screws & 403 & 534 & & 249 & 350 & & 184 & 217 & \\
\hline $\begin{array}{l}\text { Mean screw diam- } \\
\text { eter (range), mm }\end{array}$ & $7.25(5.5-8.5)$ & $6.72(5.5-8.5)$ & $<0.001$ & $7.11(5.5-8.5)$ & $6.74(6.0-8.5)$ & $<0.001$ & $7.52(5.5-8.5)$ & $6.68(5.5-8.5)$ & $<0.001$ \\
\hline $\begin{array}{l}\text { Mean screw length } \\
\text { (range), } \mathrm{mm}\end{array}$ & $48.4(40-60)$ & $45.6(35-55)$ & $<0.001$ & $47.8(40-60)$ & $45.5(35-55)$ & $<0.001$ & $49.0(40-60)$ & $45.5(35-50)$ & $<0.001$ \\
\hline
\end{tabular}

Boldface type indicates statistical significance. 
TABLE 5. Screw deviations for RN and ION-alone MIS-TLIFs

\begin{tabular}{lccc}
\hline \multirow{2}{*}{ Deviation } & \multicolumn{2}{c}{ No. of Screws (\%) } & \\
\cline { 2 - 3 } & $\mathrm{RN}$ & ION & p Value \\
\hline Superior/lateral & $11(31.4)$ & $87(54.7)$ & 0.243 \\
\hline Inferior/medial & $16(45.7)$ & $27(17.0)$ & $\mathbf{0 . 0 0 2}$ \\
\hline Tip & $8(22.9)$ & $45(28.3)$ & 0.783 \\
\hline
\end{tabular}

Boldface type indicates statistical significance. The direction of deviation is reported for all screws that were not perfectly intrapedicular (Gertzbein-Robbins grades B-E; Table 4).

(5.4 mm-6.4 mm). ${ }^{29}$ Similarly, a biomechanical model by Viezens et al. demonstrated that increasing pedicle screw diameter, from $6 \mathrm{~mm}$ to 8,9 , or $10 \mathrm{~mm}$, resulted in a $36 \%$ mean increase in fatigue load; this effect was more dramatic in osteoporotic specimens. ${ }^{4}$ While these examples are limited in their cadaveric nature, they support the well-accepted notion that using larger screws can enhance construct stiffness. The effect of circumferential fixation on obtaining successful radiographic fusion in the lumbar spine has been well demonstrated in the literature. ${ }^{30-32} \mathrm{In}$ the setting of 1- and 2-level MIS-TLIF, placement of the "ideal" pedicle screw may maximize construct stability and, thereby, prevent undue motion in the time it takes to obtain interbody fusion.

Placement of larger pedicle screws entails unique considerations. Namely, intraoperative fluoroscopic interpretation of pedicle screw position must consider screw length, starting position, and trajectory. Classically, screws crossing the midline on an anteroposterior fluoroscopic image were thought to have a medial breach. ${ }^{33,34}$ However, it is the senior author's experience that, with an "optimized" intrapedicular path and length, clinically safe and acceptable screws may indeed cross the midline. In Fig. 2, an exemplary case shows intraoperative anteroposterior imaging demonstrating that the left L3 pedicle screw crossed the midline lateral to medial; however, a postoperative CT demonstrated no evidence of a medial breach. In addition, t-EMG stimulation was performed with no response at 20 $\mathrm{mA}$ for the L4 or L5 screws bilaterally.

Results from the present study support the growing body of evidence demonstrating the high accuracy of pedicle screw instrumentation with modern technology. Historical rates of pedicle screw malposition vary significantly, depending on the technique employed (either open or percutaneous), the anatomical region in question, and the use of fluoroscopy or navigation.,.$^{2,35-37}$ The definition of a "malpositioned" screw is similarly heterogeneous. While there are several reported grading systems, many screws that deviate from a categorized "ideal" trajectory have excellent biomechanical purchase. Several studies have reported Gertzbein-Robbins grades of A and B to be clinically acceptable $(<2 \mathrm{~mm} \text { of pedicle breach) })^{8,38}$ Given this, the results from this series were comparable with the prior rates of acceptable screw placement of $80 \%$ to $100 \% .8,13,37,39$

Interestingly, we found an increased rate of both endplate breach and facet joint violation in the RN group compared with the ION group, with rates of $6.9 \%$ versus $1.3 \%$ $(\mathrm{p}<0.001)$ and $5.0 \%$ versus $1.3 \%(\mathrm{p}<0.001)$, respectively. Facet joint violation, specifically at the terminal ends of a construct, carries the risk of increased loading, stress, and more rapid degeneration of adjacent levels..$^{37,40,41}$ Despite a higher rate of facet joint violation and endplate breach in the present RN cohort, only $4.9 \%(n=5)$ of all the RN screws were graded as poor; therefore, the majority of violations or breaches occurred within the fusion construct, making their placement clinically acceptable. The rate of poor screws was $5.2 \%(n=24)$ in the ION group. This difference did not reach statistical significance $(\mathrm{p}=0.882)$, again demonstrating the similarity in safety profiles between the RN and ION cohorts. While the present analysis demonstrated a higher rate of facet joint violation in the $\mathrm{RN}$ cohort, these results are comparable to those of other reported series. A recent meta-analysis assessed the safety of robot-assisted pedicle screw placement compared with a traditional, freehand technique. From the four included studies, the authors reported $92 \%$ fewer facet joint violations with robotic assistance..$^{42}$ Similarly, Katsevman et al. reported a facet joint violation rate of $3.7 \%$ for 54 robotically placed screws in the lumbar spine, compared with $11.9 \%$ (5/42 screws) in their freehand, control group..$^{37}$

The present study is not without limitations. First, the clinical impact of the larger-diameter and longer screws used in the RN cohort remains uncertain. The biomechanical advantages of larger screws are well accepted and become more essential when using interbody fusion techniques. Obtaining successful fusion depends largely on the stability of the overall construct, as a low-strain mechanical environment must be maintained to facilitate the healing process ${ }^{43}$ Optimizing this environment during MIS-TLIF is critical since performing concomitant posterolateral fusion is not an option, as is often used with open TLIF. ${ }^{44}$ Furthermore, prior studies have demonstrated limited interbody space preparation with MIS techniques compared with open technique. ${ }^{44-47}$ As such, posterior pedicle fixation becomes more critical during the reparative/remodeling phase following interbody placement in MIS-TLIF. Placement of the largest screws

TABLE 6. Endplate breach, facet violation, and overall placement grades for pedicle screws for RN and ION-alone MIS-TLIFs

\begin{tabular}{|c|c|c|c|c|c|c|c|}
\hline & \multicolumn{2}{|c|}{ Endplate Breach } & \multicolumn{2}{|c|}{ Facet Violation } & \multicolumn{3}{|c|}{ Overall Placement } \\
\hline & Yes & No & Yes & No & Good & Acceptable & Poor \\
\hline $\mathrm{RN}, \mathrm{n}(\%)$ & $7(6.9)$ & $95(93.1)$ & $5(5.0)$ & $96(95.0)$ & $65(63.7)$ & $32(31.4)$ & $5(4.9)$ \\
\hline ION, n (\%) & $6(1.3)$ & $449(98.7)$ & $6(1.3)$ & $453(98.7)$ & $301(66.1)$ & $131(28.7)$ & $24(5.2)$ \\
\hline$p$ value & \multicolumn{2}{|c|}{0.001} & \multicolumn{2}{|c|}{0.0017} & 0.661 & 0.595 & 0.882 \\
\hline
\end{tabular}

Boldface type indicates statistical significance. 

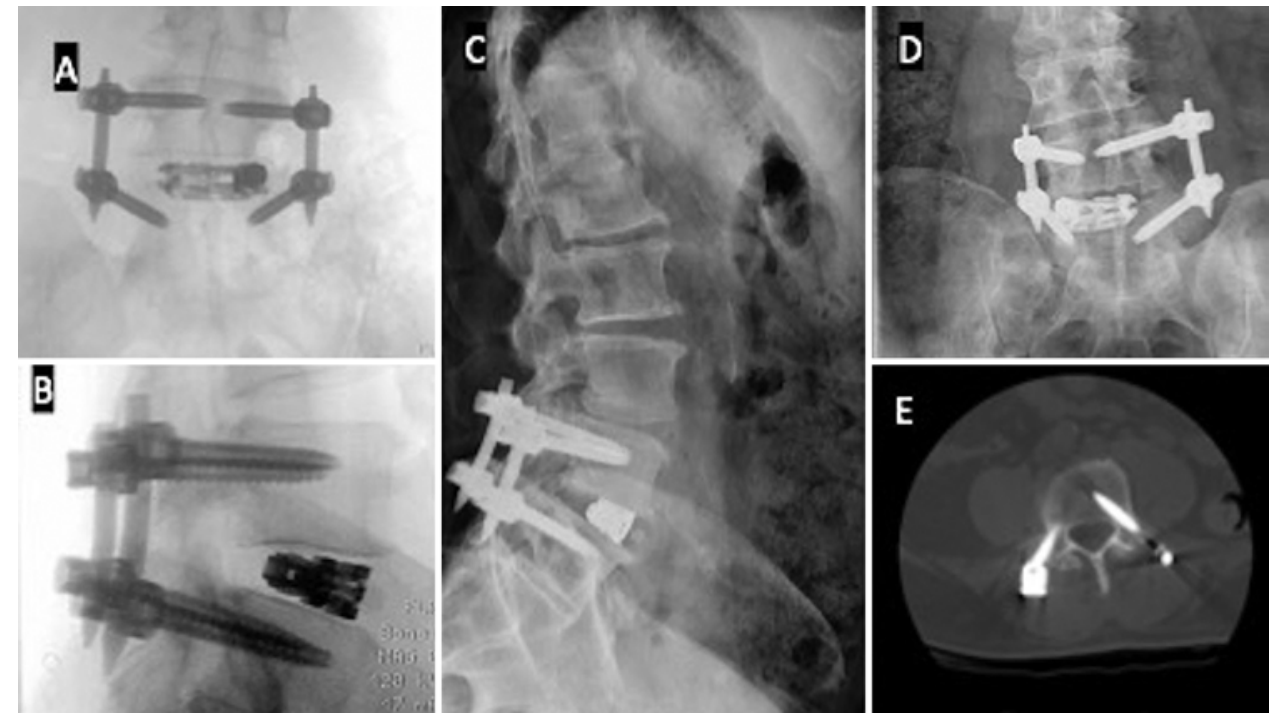

FIG. 2. Imaging obtained in a 72-year-old male who underwent RN MIS-TLIF for symptomatic spinal stenosis at L4-5 with associated degenerative scoliosis. A: Intraoperative posteroanterior fluoroscopic image demonstrating crossing of the midline by the left L4 screw. B-D: Intrapedicular position was confirmed in a lateral fluoroscope image (B) as well as postoperative standing anteroposterior (C) and lateral (D) radiographs. Again, the left L4 screw is visible crossing the midline (D). E: Postoperative axial CT section demonstrating an intrapedicular trajectory without evidence of cortical violation.

technically possible should, in theory, provide the most favorable environment to support healing. However, future high-fidelity studies are warranted to establish both the clinical and radiographic utility of larger screws.

Second, all surgeries in this series were performed by a fellowship-trained attending spine surgeon, with more than 10 years of experience with these techniques. Similarly, only one robotic platform and one navigation system were utilized. While this provides homogeneity in surgical workflow and screw selection, the generalizability of the above findings may be limited. Familiarity with both the surgical technique and robotic interface may be a requirement to confidently place "optimal" screws. Given the range of experience among spine surgeons, not every user may be able to maximize the benefits of robotic platforms to the same extent.

\section{Conclusions}

These findings highlight the ability to visualize and optimize screw trajectories and dimensions intraoperatively with robotic assistance. This may allow surgeons to better select and place the "optimal" screw, while maintaining a high level of safety and accuracy. While the clinical significance of these findings will need to be fully elucidated, the biomechanical properties offered by larger screws may provide a more stable environment for achieving successful fusion and, subsequently, improved clinical outcomes. Furthermore, as robotic platforms become more popular, surgeons should be comfortable and confident in their screw selection, particularly when using sizes that they may have previously thought too large.

\section{Acknowledgments}

No direct funding was received for this study. However, this study used REDCap hosted at Weill Cornell Medicine Clinical and Translational Science Center supported by the NIH's National Center for Advancing Translational Science under award number UL1 TR002384.

\section{References}

1. Tannous O, Jazini E, Weir TB, Banagan KE, Koh EY, Greg Anderson D, et al. Facet joint violation during percutaneous pedicle screw placement: a comparison of two techniques. Spine (Phila Pa 1976). 2017;42(15):1189-1194.

2. Perdomo-Pantoja A, Ishida W, Zygourakis C, Holmes C, Iyer RR, Cottrill E, et al. Accuracy of current techniques for placement of pedicle screws in the spine: a comprehensive systematic review and meta-analysis of 51,161 screws. World Neurosurg. 2019;126:664-678.e3.

3. Hirano T, Hasegawa K, Takahashi HE, Uchiyama S, Hara T, Washio T, et al. Structural characteristics of the pedicle and its role in screw stability. Spine (Phila Pa 1976). 1997;22(21): 2504-2510.

4. Viezens L, Sellenschloh K, Püschel K, Morlock MM, Lehmann W, Huber G, Weiser L. Impact of screw diameter on pedicle screw fatigue strength-a biomechanical evaluation. World Neurosurg. 2021;152:e369-e376.

5. Kirkaldy-Willis WH, Wedge JH, Yong-Hing K, Reilly J. Pathology and pathogenesis of lumbar spondylosis and stenosis. Spine (Phila Pa 1976). 1978;3(4):319-328.

6. Becker S, Chavanne A, Spitaler R, Kropik K, Aigner N, Ogon M, Redl H. Assessment of different screw augmentation techniques and screw designs in osteoporotic spines. Eur Spine J. 2008; 17(11):1462-1469.

7. Karapinar L, Erel N, Ozturk H, Altay T, Kaya A. Pedicle screw placement with a free hand technique in thoracolumbar spine: is it safe? J Spinal Disord Tech. 2008;21(1):63-67.

8. Schatlo B, Molliqaj G, Cuvinciuc V, Kotowski M, Schaller $\mathrm{K}$, Tessitore E. Safety and accuracy of robot-assisted versus fluoroscopy-guided pedicle screw insertion for degenerative diseases of the lumbar spine: a matched cohort comparison. $J$ Neurosurg Spine. 2014;20(6):636-643. 
9. Fan Y, Du JP, Liu JJ, Zhang JN, Qiao HH, Liu SC, Hao DJ. Accuracy of pedicle screw placement comparing robot-assisted technology and the free-hand with fluoroscopy-guided method in spine surgery: an updated meta-analysis. Medicine (Baltimore). 2018;97(22):e10970.

10. Huntsman KT, Riggleman JR, Ahrendtsen LA, Ledonio CG. Navigated robot-guided pedicle screws placed successfully in single-position lateral lumbar interbody fusion. J Robot Surg. 2020;14(4):643-647.

11. Keric N, Doenitz C, Haj A, Rachwal-Czyzewicz I, Renovanz M, Wesp DMA, et al. Evaluation of robot-guided minimally invasive implantation of 2067 pedicle screws. Neurosurg Focus. 2017;42(5):E11.

12. Bovonratwet P, Gu A, Chen AZ, Samuel AM, Vaishnav AS, Sheha ED, et al. Computer-assisted navigation is associated with decreased rates of hardware-related revision after instrumented posterior lumbar fusion. Global Spine J. Published online June 23, 2021. doi:10.1177/21925682211019696

13. McKenzie DM, Westrup AM, O'Neal CM, Lee BJ, Shi HH, Dunn IF, et al. Robotics in spine surgery: a systematic review. J Clin Neurosci. 2021;89:1-7.

14. Avrumova F, Sivaganesan A, Alluri RK, Vaishnav A, Qureshi S, Lebl DR. Workflow and efficiency of robotic-assisted navigation in spine surgery. HSS J. 2021;17(3):302-307.

15. Louie PK, Vaishnav AS, Gang CH, Urakawa H, Sato K, Chaudhary $\mathrm{C}$, et al. Development and initial internal validation of a novel classification system for perioperative expectations following minimally invasive degenerative lumbar spine surgery. Clin Spine Surg. 2021.

16. Reddy RP, Chang R, Coutinho DV, Meinert JW, Anetakis $\mathrm{KM}$, Crammond DJ, et al. Triggered electromyography is a useful intraoperative adjunct to predict postoperative neurological deficit following lumbar pedicle screw instrumentation. Global Spine J. Published online May 20, 2021. doi: 10.1177/21925682211018472

17. Barsotti CE, Gavassi BM, Prado FE, Batista BN, de Resende Pratali R, Ribeiro AP, et al. Diagnostic accuracy of perioperative electromyography in the positioning of pedicle screws in adolescent idiopathic scoliosis treatment: a cross-sectional diagnostic study. BMC Musculoskelet Disord. 2020;21(1):473.

18. Harris PA, Taylor R, Minor BL, Elliott V, Fernandez M, O'Neal L, et al. The REDCap consortium: building an international community of software platform partners. J Biomed Inform. 2019;95:103208.

19. Virk S, Qureshi S. Navigation in minimally invasive spine surgery. J Spine Surg. 2019;5(1)(suppl 1):S25-S30.

20. Vaishnav AS, Merrill RK, Sandhu H, McAnany SJ, Iyer S, $\mathrm{Gang} \mathrm{CH}$, et al. A review of techniques, time demand, radiation exposure, and outcomes of skin-anchored intraoperative 3D navigation in minimally invasive lumbar spinal surgery. Spine (Phila Pa 1976). 2020;45(8):E465-E476.

21. Vaishnav AS, Saville P, McAnany S, Kirnaz S, Wipplinger C, Navarro-Ramirez R, et al. Retrospective review of immediate restoration of lordosis in single-level minimally invasive transforaminal lumbar interbody fusion: a comparison of static and expandable interbody cages. Oper Neurosurg ( $\mathrm{Ha}$ gerstown). 2020;18(5):518-523.

22. Vaishnav AS, Gang CH, Qureshi SA. Time-demand, radiation exposure and outcomes of minimally invasive spine surgery with the use of skin-anchored intraoperative navigation: the effect of the learning curve. Clin Spine Surg. 2021.

23. Vaccaro AR, Harris JA, Hussain MM, Wadhwa R, Chang VW, Schroerlucke SR, et al. Assessment of surgical procedural time, pedicle screw accuracy, and clinician radiation exposure of a novel robotic navigation system compared with conventional open and percutaneous freehand techniques: a cadaveric investigation. Global Spine J. 2020;10(7):814-825.

24. Weiner JA, McCarthy MH, Swiatek P, Louie PK, Qureshi SA. Narrative review of intraoperative image guidance for transforaminal lumbar interbody fusion. Ann Transl Med. 2021;9(1):89.

25. Jiang B, Karim Ahmed A, Zygourakis CC, Kalb S, Zhu AM, Godzik J, et al. Pedicle screw accuracy assessment in ExcelsiusGPS $®$ robotic spine surgery: evaluation of deviation from pre-planned trajectory. Chin Neurosurg J. 2018;4:23.

26. Alluri RK, Avrumova F, Sivaganesan A, Vaishnav AS, Lebl DR, Qureshi SA. Overview of robotic technology in spine surgery. HSS J. 2021;17(3):308-316.

27. Cong T, Sivaganesan A, Mikhail CM, Vaishnav AS, Dowdell J III, Barbera J, et al. Facet violation with percutaneous pedicle screw placement: impact of 3D navigation and facet orientation. HSS J. 2021;17(3):281-288.

28. Wittenberg RH, Lee KS, Shea M, White AA III, Hayes WC. Effect of screw diameter, insertion technique, and bone cement augmentation of pedicular screw fixation strength. Clin Orthop Relat Res. 1993;(296):278-287.

29. Kueny RA, Kolb JP, Lehmann W, Püschel K, Morlock MM, Huber G. Influence of the screw augmentation technique and a diameter increase on pedicle screw fixation in the osteoporotic spine: pullout versus fatigue testing. Eur Spine J. 2014; 23(10):2196-2202.

30. Kim DH, Hwang RW, Lee GH, Joshi R, Baker KC, Arnold $\mathrm{P}$, et al. Comparing rates of early pedicle screw loosening in posterolateral lumbar fusion with and without transforaminal lumbar interbody fusion. Spine J. 2020;20(9):1438-1445.

31. Enker P, Steffee AD. Interbody fusion and instrumentation. Clin Orthop Relat Res. 1994;(300):90-101.

32. Mummaneni PV, Haid RW, Rodts GE. Lumbar interbody fusion: state-of-the-art technical advances. Invited submission from the Joint Section Meeting on Disorders of the Spine and Peripheral Nerves, March 2004. J Neurosurg Spine. 2004; 1(1):24-30.

33. Chong XL, Kumar A, Yang EWR, Kaliya-Perumal AK, Oh JYL. Incidence of pedicle breach following open and minimally invasive spinal instrumentation: A postoperative CT analysis of 513 pedicle screws applied under fluoroscopic guidance. Biomedicine (Taipei). 2020;10(2):30-35.

34. Nevzati E, Marbacher S, Soleman J, Perrig WN, Diepers M, Khamis A, Fandino J. Accuracy of pedicle screw placement in the thoracic and lumbosacral spine using a conventional intraoperative fluoroscopy-guided technique: a national neurosurgical education and training center analysis of 1236 consecutive screws. World Neurosurg. 2014;82(5):866-71.e1, 2.

35. Gautschi OP, Schatlo B, Schaller K, Tessitore E. Clinically relevant complications related to pedicle screw placement in thoracolumbar surgery and their management: a literature review of 35,630 pedicle screws. Neurosurg Focus. 2011;31(4):E8.

36. Kosmopoulos V, Schizas C. Pedicle screw placement accuracy: a meta-analysis. Spine (Phila Pa 1976). 2007;32(3):E111-E120.

37. Katsevman GA, Spencer RD, Daffner SD, Bhatia S, Marsh RA, France JC, et al. Robotic-navigated percutaneous pedicle screw placement has less facet joint violation than fluoroscopy-guided percutaneous screws. World Neurosurg. 2021;151:e731-e737.

38. Solomiichuk V, Fleischhammer J, Molliqaj G, Warda J, Alaid A, von Eckardstein K, et al. Robotic versus fluoroscopyguided pedicle screw insertion for metastatic spinal disease: a matched-cohort comparison. Neurosurg Focus. 2017;42(5):E13.

39. Fan Y, Peng Du J, Liu JJ, Zhang JN, Liu SC, Hao DJ. Radiological and clinical differences among three assisted technologies in pedicle screw fixation of adult degenerative scoliosis. Sci Rep. 2018;8(1):890.

40. Kim HJ, Chun HJ, Kang KT, Moon SH, Kim HS, Park JO, et al. The biomechanical effect of pedicle screws' insertion angle and position on the superior adjacent segment in 1 segment lumbar fusion. Spine (Phila Pa 1976). 2012;37(19):1637-1644.

41. Iyer S, Kim HJ, Theologis A, Nemani VM, Albert TJ, Lenke LG, et al. Outcomes of fusions from the cervical spine to the pelvis. Global Spine J. 2019;9(1):6-13. 
42. Fatima N, Massaad E, Hadzipasic M, Shankar GM, Shin JH. Safety and accuracy of robot-assisted placement of pedicle screws compared to conventional free-hand technique: a systematic review and meta-analysis. Spine J. 2021;21(2):181-192.

43. Boden SD, Titus L, Hair G, Liu Y, Viggeswarapu M, Nanes MS, Baranowski C. Lumbar spine fusion by local gene therapy with a cDNA encoding a novel osteoinductive protein (LMP-1). Spine (Phila Pa 1976). 1998;23(23):2486-2492.

44. Lee MJ, Mok J, Patel P. Transforaminal lumbar interbody fusion: traditional open versus minimally invasive techniques. $J$ Am Acad Orthop Surg. 2018;26(4):124-131.

45. Peng CWB, Yue WM, Poh SY, Yeo W, Tan SB. Clinical and radiological outcomes of minimally invasive versus open transforaminal lumbar interbody fusion. Spine (Phila $\mathrm{Pa}$ 1976). 2009;34(13):1385-1389.

46. Kim CH, Easley K, Lee JS, Hong JY, Virk M, Hsieh PC, Yoon ST. Comparison of minimally invasive versus open transforaminal interbody lumbar fusion. Global Spine $J$. 2020;10(2)(suppl):143S-150S.

47. Mobbs RJ, Phan K, Malham G, Seex K, Rao PJ. Lumbar interbody fusion: techniques, indications and comparison of interbody fusion options including PLIF, TLIF, MI-TLIF, OLIF/ATP, LLIF and ALIF. J Spine Surg. 2015;1(1):2-18.

\section{Disclosures}

Dr. Qureshi: royalties from Stryker K2M, Zimmer Biomet, and Globus Medical, Inc.; private investments in Tissue Differentiation Intelligence and HS2; consultant for Stryker K2M, Globus Medical, Inc., and Simplify Medical; speaking and/ or teaching arrangements with AMOpportunities and Globus Medical, Inc.; board of directors of Society of Minimally Invasive Spine Surgery; and scientific advisory board/other office for
International Society for the Advancement of Spine Surgery, Cervical Spine Research Society, Lumbar Spine Research Society, North American Spine Society, Association of Bone and Joint Surgeons, Simplify Medical, Inc., LifeLink.com, Inc., Society of Minimally Invasive Spine Surgery, Minimally Invasive Spine Study Group, Spinal Simplicity, LLC, Contemporary Spine Surgery, and Annals of Translational Medicine.

\section{Author Contributions}

Conception and design: Qureshi. Acquisition of data: all authors. Analysis and interpretation of data: all authors. Drafting the article: Shafi, Pompeu, Vaishnav, Mai, Sivaganesan. Critically revising the article: all authors. Reviewed submitted version of manuscript: all authors. Approved the final version of the manuscript on behalf of all authors: Qureshi. Statistical analysis: Mai, Shafi, Vaishnav. Administrative/technical/material support: Qureshi, Mai, Shahi. Study supervision: Qureshi, Sivaganesan.

\section{Supplemental Information \\ Videos \\ Video Abstract. https://vimeo.com/656138388.}

\section{Correspondence}

Sheeraz Qureshi: Hospital for Special Surgery, New York, NY. sheerazqureshimd@gmail.com. 